\title{
SARANA-OLAHRAGA VERTIKAL JAKARTA
}

\author{
$\operatorname{Tian}^{1)}$, Suwardana Winata ${ }^{2)}$ \\ 1)Program Studi S1 Arsitektur, Fakultas Teknik, Universitas Tarumanagara, lai.tian@ymail.com \\ 2) Program Studi S1 Arsitektur, Fakultas Teknik, Universitas Tarumanagara, danarsitek@gmail.com
}

\begin{abstract}
Abstrak
Generasi Millennial (Gen-Y) merupakan generasi yang lahir antara tahun 1981-1994, yang menjadi masyarakat dominan dan sedang dalam masa produktif mereka. Generasi millennial yang tidak terhindarkan dari otomatisasi, yang membuat segala kegiatan dan kebutuhan menjadi lebih mudah dan cepat, terlebih lagi banyak kegiatan yang dapat dilakukan secara bersamaan dengan adanya otomatisasi ini. Kebiasaan ini kian menjadi gaya hidup generasi millennial yang bahkan sangat bergantung kepada kemajuan teknologi yang ada sekarang dan yang akan datang. Selayaknya manusia sebagai makhluk hidup yang punya keterbatasan untuk berkembang yang bertolak belakang dengan teknologi sekarang yang terus meningkat, yang berarti generasi millennial ini sedikit demi sedikit akan kehilangan kemampuan mereka untuk mengikuti laju perkembangan teknologi tersebut. Kesehatan menjadi kunci generasi millennial untuk tetap dapat beraktivitas dan mengikuti perkembangan teknologi saat ini. Dengan menciptakan sebuah sarana olahraga yang berfungsi sebagai sarana rekreasi dan kesehatan dari padatnya aktivitas di daerah Jakarta Pusat, tepatnya pada Jl. H. Agus Salim, pendekatan desain yang memfokuskan kepada penyediaan ruang yang dapat digunakan untuk berolahraga yang dapat di tempatkan di tengah kota untuk menjawab keterjangkauan sarana olahraga ini, dengan harapan dapat menyeimbangkan kebutuhan generasi millennial akan sarana rekreasi dari padatnya aktivitas di tengah kota.
\end{abstract}

Kata kunci: Jakarta; Milenial; Olahraga; Rekreasi

\begin{abstract}
The Millennials, also known as Generation $Y(G e n-Y)$ refer to a generation with people who were born in between 1981-1994, in which they have become dominant in the society and are in their productive phase. The millennials are certainly inevitable from the existence of automation resulting in an easier and faster way in doing various activities and fulfilling needs, moreover, many activities can be carried out simultaneously with the existence of this automation. This habit is increasingly becoming the lifestyle of these millennials in which they are heavily dependent on current and future technological advancements. For that matter, human beings are living things that have limits in terms of developing meanwhile, technologies currently are rapidly advancing. This means that these millennials will gradually lose their ability to keep track of the development of these technologies. Health is one of the keys for these millennials to be able to carry out activities and keep up with current technological developments. By creating a sports facility that functions as a means of recreation and health in the midst of the dense activities in Central Jakarta, precisely in Jl. H. Agus Salim, a design approach that focuses on providing space that can be used for sports and can be placed in the middle of the city, is given out to satisfy the necessity of having this kind of facility, in the hope of balancing the needs of these millennials for recreation in the middle of their crowded activities in the city.
\end{abstract}

Keywords: Jakarta; Millennials; Recreation; Sport

\section{PENDAHULUAN \\ Latar Belakang}

Generasi Millennial (Gen-Y) merupakan generasi yang lahir antara tahun 1981-1994, yang menjadi masyarakat dominan dan sedang dalam masa produktif mereka. Ciri generasi millennial yang umum adalah keterbukaan dan kemmapuan generasi ini dalam mengakses internet. Membentuk hubungan yang saling tekoneksi tanpa ada batasan jarak, perkembangan pada bidang teknologi lain juga berdampak pada gaya hidup yang menuntut serba cepat dan multitasking, generasi ini juga sangat identik dalam Perkembangan teknologi membuat usaha 
generasi millennial untuk memenuhi kebutuhan mereka semakin dekat dan semakin cepat, dampaknya Generasi millennial yang tidak terhindarkan dari otomatisasi, yang membuat segala kegiatan dan kebutuhan menjadi lebih mudah dan cepat, terlebih lagi banyak kegiatan yang dapat dilakukan secara bersamaan dengan adanya otomatisaasi ini.

Generasi ini berkembang semakin cepat karena semakin banyak kegiatan serta kebutuhan yang dapat terpenuhi dengan mudah dan cepat, generasi millennial menjadi generasi yang tepelajar karena semua pengetahuan dan kebutuhan dapat dengan mudah di akses dan di sebarluaskan, konektivitas ini membuat segala sesuatu seperti di gengaman tangan.Peristiwa ini sudah menjadi budaya generasi millennial ini dari memenuhi kebutuhan individual mereka hingga kebutuhan interaksi dengan masyarakat luas yang mempunyai kebutuhan yang sama untuk membentuk sebuah ikatan sosial secara real maupun virtual.

Dengan tujuan serta kebutuhan yang sama inilah, masyarakat tanpa sadar membentuk kumpulan yang berfokus kepada satu tujuan yang membuat mereka saling bertemu serta saling mendukung. Semakin banyak variasi dalam hal kebutuhan yang ada menjadikan generasi ini saling membentuk kumpulan mereka masing-masing. Dengan keberagaman kumpulan ini membuat setiap kumpulan tersebut lebih mudah menjalin kerjasama untuk saling memenuhi kebutuhan masing-masing pihak, semkain banyak pihak terlibat akan semakin cepat pula pemenuhan tujuan mereka. Setelah semakin banyak perpaduan-perpaduan tersebut generasi millennial menuju ketahap dimana pemenuhan kebutuhan sudah bukan menjadi halangan, akibatnya pengalaman (proses) perlahan mulai menghilang. Kekurangan pengalaman ini berasal dari maraknya perkembangan otomatiasi yang membuat generasi millennial tidak mengalami proses dari pemenuhan kebutuhan mereka. Perkembangan serba instant menjadi sebutan lain bagi generasi millennial yang selalu mendapatkan kebutuhan mereka dengan cepat dan mudah, tetapi tanpa mengetahui proses dari setiap kebutuhan mereka yang telah terpenuhi.

Generasi millennial sangat maju dalam hal pengetahuan dan teknologi tetapi kekurangan pengalaman untuk dapat mengalami sebuah proses (cara) untuk mendapatkan kebutuhan mereka, pengaruh ini menjadikan sebagian besar generasi millennial memilih bekarya dari kreativitas mereka di banding menerapkan idenya sendiri. Kebutuhan otomatisasi ini bukan hanya membentuk masyarakat menjadi serba cepat dan semakin mudah, sebagai dampak baik dari perkembangan di generasi millennial ini dari banyaknya teknologi yang dihasilkan untuk memudahkan masyarakat lokal hingga dunia, tetapi ada pula dampak buruk dari perkembangan otomatisasi ini. Munculnya otomatisasi yang membentuk karakter generasi millennial ini menjadi lebih jarang bergerak untuk memenuhi kebutuhan-kebutuhan karena teknologi yang sekarang tersedia dan tersebar luas seperti internet.

Kebiasaan ini menjadi gaya hidup generasi millennial yang bahkan sangat bergantung kepada kemajuan teknologi yang ada sekarang dan yang akan datang. Selayaknya manusia sebagai makhluk hidup yang punya kapasitas yang tidak seperti perkembangan teknologi sekarang yang terus menanjak, yang berarti generasi millennial ini sedikit demi sedikit akan kehilangan kemampuan mereka untuk mengikuti laju perkembangan teknologi tersebut. Untuk itu selain mengembangkan kemampuan teknologi sebagai alat yang dapat memudahkan segala pekerjaan dan kebutuhan manusia, manusia juga perlu mempertahankan dan memaksimalkan kemampuan mereka untuk megikuti laju perkembangan teknologi dengan menjaga tubuh fisik mereka masingmasing.

Vertical gymnasium sebagai sarana rekreasi yang ditujukan kepada masyarakat untuk merelaksasikan diri dengan berolahraga, karena dengan berolahraga seseorang akan memicu adrenaline dari aktivitas fisik yang dilakukan dan pada saat yang sama adarenaline juga memicu hormone endorphine yang akhirnya akan membawa suasana relaksasi saat ber-olahraga. Olahraga-olahraga pada vertical gymnasium dibuat sebagai lapangan terbuka yang dapat digunakan bersama-sama untuk membangun komunitas untuk berekreasi dan berinteraksi dengan orang lain. Berolahraga juga sebagai aktivitas yang dibutuhkan untuk menjaga kebugaran dan kesehatan tubuh masyarakat di segala golongan usia, kebutuhan rekreasi bertujuan untuk 
menenangkan pikirin dan fisik yang umunya karena pekerjaan-pekerjaan yang kurang menuntut untuk bergerak.

Vertical gymnasium sebagai pusat kebugaran dan rekreasi yang menargetkan masyarakat yang kesehariannya sibuk dengan pekerjaannya, sebagai keterjangkauan sarana rekreasi, maka dari itu penempatan di Jakarta Pusat sebagai penetral dari kegiatan perkantoran di Jakarta Pusat. Sebagai bangunan untuk menampung berbagai golongan masyarakat penempatan di dekat dengan fasilitas-fasilitas transportasi juga sangat penting untuk pencapaian, maka dari itu Jl. H.Agus Salim yang memenuhi kriteria-kriteria yang ada.

Semakin padatnya kawasan Jakarta pusat sebagai kawasan perkantoran yang di dominasi gedung-gedung tinggi membuat nilai ekonomis dari tanah di daerah Jakarta pusat cukup mahal, sebagai strategi untuk memanfaatkan nilai tanah pembangunan gedung tinggi. Untuk menjawab kebutuhan olahraga rekreasi dan membangun komunitas untuk saling berinteraksi, olahraga yang dipilih berdasarkan olahraga grup, selain itu olahraga-olahraga yang dapat mainkan berbagai golongan umur. Berdasarkan masalah yang timbul di masyarakat dalam bidang rekreasi khususnya di Jakarta Pusat yang dominasi oleh aktivitas perkantoran. Diharapkan Vertical Gymnasium dapat menjadi salah satu sarana untuk memenuhi kebutuhan rekreasi dan kesehatan masyarakat, serta menciptakan interaksi antar individu menjadi komunitas.

\section{Susunan Penulisan}

Keperluan data untuk mendukung penyusunan laporan, antara lain: data-data mengenai kebutuhan manusia khususnya generasi millennial, data-data mengenai ciri dan karakter generasi millennial, data-data lokasi yang dapat digunakan untuk menjawab kriteria perancangan, data-data peraturan kota dan daerah untuk menjadi acuan perancangan. Pada umumnya di usia millennial sekarang yang sudah memasuki usia produktif bekerja dan sudah mendapat gelar sarjana dan mulai mencari pekerjaan di Jakarta pusat.

Lingkungan yang tepat untuk menjadi saran rekreasi yang akan sering di lalui untuk memenuhi keterjangkauan lokasi seperti pada zona transit transportasi umum maupun pribadi, sedangkan untuk melihat kelengkapan fasilitas lingkungan untuk mendukung program rekreasi dibutuhkan lingkungan yang juga menyediakan program demikian yang tidak membuat masyarakat sekitar memiliki tujuan rekreasi lebih dari pada tujuan untuk bekerja atau hanya sebagai jalur transportasi mereka. Lokasi tapak berada di jalan H. Agus Salim yang merupakan jalan sekunder dari jalan M.H. Thamrin, lokasi terpilih seluas $\pm 2.500 \mathrm{M}^{2}$, Dari hasil survei di atas, fungsi-fungsi di ingkungan sekitar cukup mendukung program rekreasi (Olahraga) dan memiliki sarana sebagai pendukung rekreasi.

Olahraga merupakan bentuk permainan yang memiliki stuktur untuk dinikmati dan di senangi, lebih jauh lagi pada masa sebelum masehi olahraga adalah aktivitas keseharian mereka dan sarana aktualisasi diri untuk menjadi yang penguasa. Olahraga telah dilihat generasi millennial menjadi kebutuhan pokok untuk memulai aktivitas, karena banyakn bukti tentang pengaruh positif olahraga untuk aktivitas mereka sehari-hari, tetapi masih banyak yang kekurangan olahraga atau malah terlalu banyak olahraga.

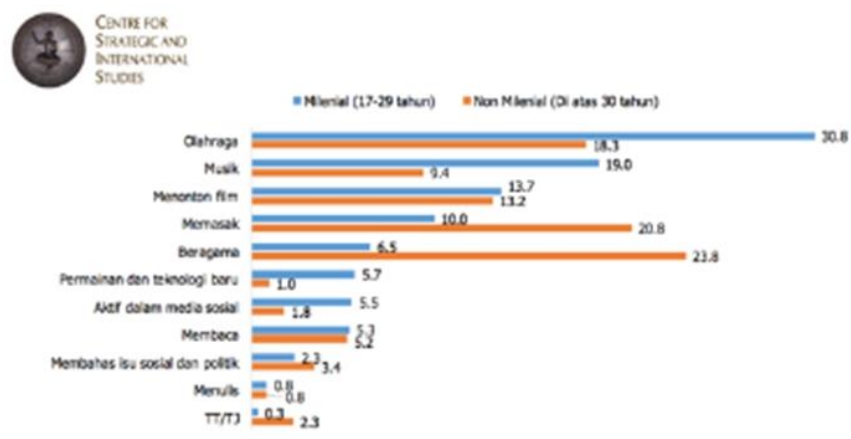

Gambar 1. Grafik kegiatan yang paling menarik minat Sumber: https://www.csis.or.id/, 2017 
Penduduk Berumur 10 Tahun ke Atas yang Rutin Berolahraga

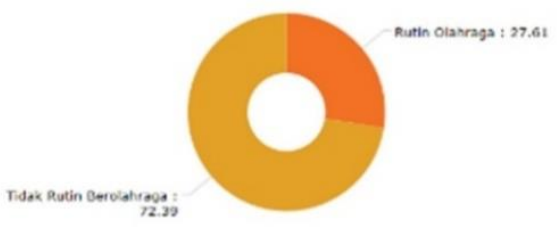

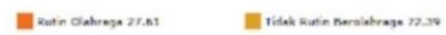

Gambar 2. Grafik jumlah penduduk Indonesia yang rutin berolahraga

Sumber: Databoks.katadata.co.id, 2015

Generasi millennial di Indonesia lebih berminat untuk menikmati olahraga tetapi tidak melakukan olahraga secara rutin (satu kali dalam seminggu), Sun Life Financial dengan LPSOS menyatakan bahwa 4 dari 5 orang di Indonesia merasa dirinya sehat, indeks untuk prioritas kesehatan pribadi juga terus meningkat, tapi kesadaran tersebut tidak diikuti oleh pola hidup sehat, karena sepertiga penduduk Indonesia masih menunjukan kebiasaan yang tidak sehat

Aktivitas olahraga juga membantu menjaga produktifitas tubuh dan pikiran, tetapi generasi millennial lebih membutuhkan olahraga untuk kebutuhan experience (pengalaman), karena olahraga sebagai ruang sosial (fisik) yang dilakukan bersama; olahraga sebagai lebutuhan kesehatan fisik setiap individu; beberapa olahraga memerlukan wadah (manusia) berbentuk ruang; dan pelepasan emosi (stress, senang, penat) atau rekreasi bagi generasi millennial. Kebutuhan olahraga pada generasi millennial juga berdampak pada kemajuan teknologi untuk bersikap cekatan di era yang serba cepat ini.

Intensitas olahraga pada setiap lapisan masyarakat sangatlah berbeda, seperti kecenderungan malas atau exhibisionis yang membuat mereka tidak dapat mengatur prioritas kebutuhan mereka sendiri. Sedangkan untuk generasi millennial yang rutin berolahraga juga punya kecenderungan untuk hanya berkumpul dengan komunitas atau untuk menjaga rutinitas harian mereka, prioritas pada kesehatan belum menjamin seseorang telah menjalankan pola hidup sehat yang benar.

Dengan membuat sarana-olahraga di Jakarta pusat untuk mendekatkan dan menyeimbangkan kebutuhan bagi masyarakat yang berada di Jakarta pusat, selain itu untuk memaksimalkan fungsi lahan pemanfaatan setiap meter persegi agar dapat digunakan semaksimal mungkin dengan cara merencanakan sarana olahraga yang bertumpuk. Pada bagian kolaboratif, sistem bangunan akan menjadi "Open Court" sehingga setiap lapangnan olahraga dapat digunakan Bersama untuk menjadi titik sosialisasi pengguna sarana olahraga ini, serta diharapakan dapat menjadi sebuah wadah organisasi positif bagi pengguna hingga lingkungan dalam hal kolaboratif.

\section{DISKUSI DAN HASIL}

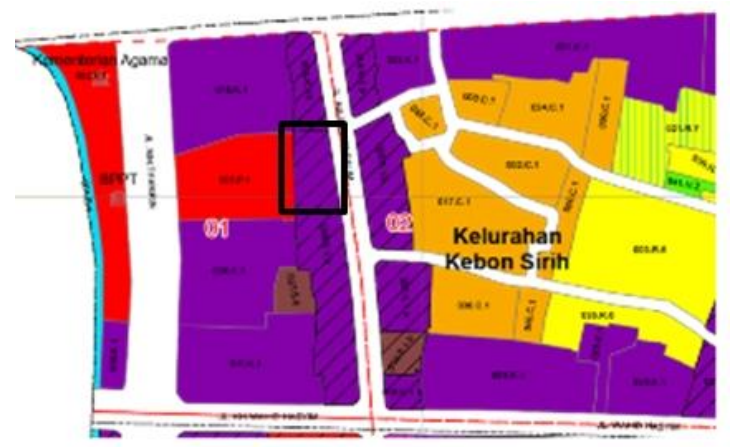

\begin{tabular}{ll} 
& KEBON SIRIH \\
\hline BLOK & 01 \\
\hline SUB BLOK & 08 \\
\hline SUB ZONA & K.1 \\
\hline ID SUBBLOK & 01.008. K.1 \\
\hline KDB & 60 \\
\hline KLB & 3.50 \\
\hline KB & 8 \\
\hline KDH & 30 \\
\hline KTB & 55 \\
\hline TIPE & D \\
\hline PSL & $P$ \\
\hline
\end{tabular}

Gambar 3. Peta Zonasi Kecamatan Menteng Kelurahan Kebon Sirih dan Zonasi Tapak Terpilih Sumber: jakartasatu.jakarta.go.id, 2019 
Lokasi tapak berada di jalan H. Agus Salim yang merupakan jalan sekunder dari jalan M.H. Thamrin, lokasi terpilih seluas $\pm 2.500 \mathrm{M}^{2}$ dengan ukuran $( \pm 57 \mathrm{M} \times 48 \mathrm{M})$.

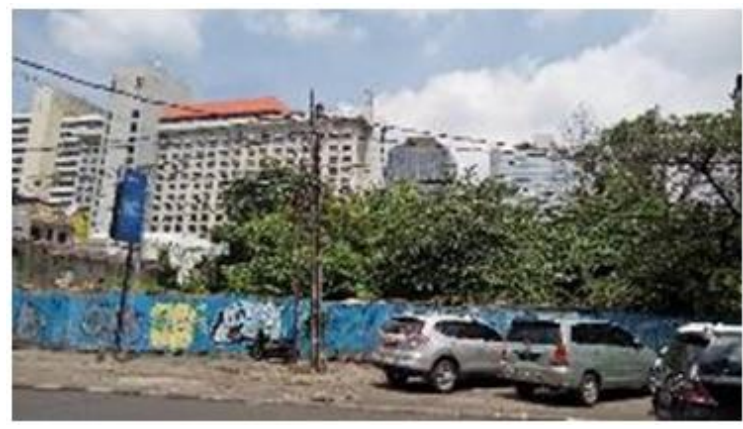

Gambar 4. Kondisi lokasi terpilih Sumber: Penulis, 2019

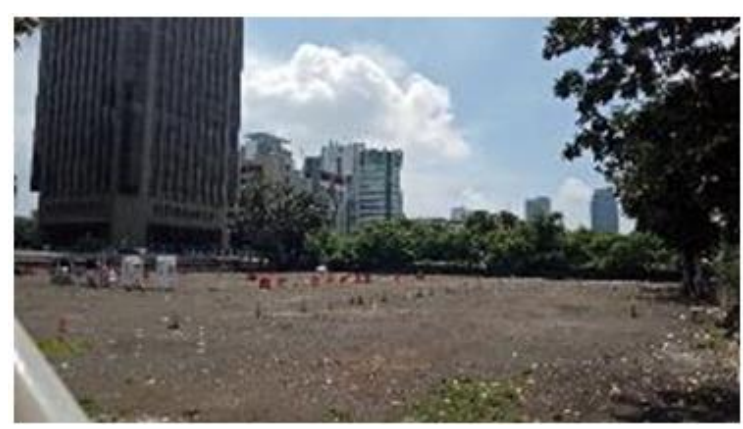

Gambar 6. Lapangan Parkir di Belakang Site Sumber: Penulis, 2019

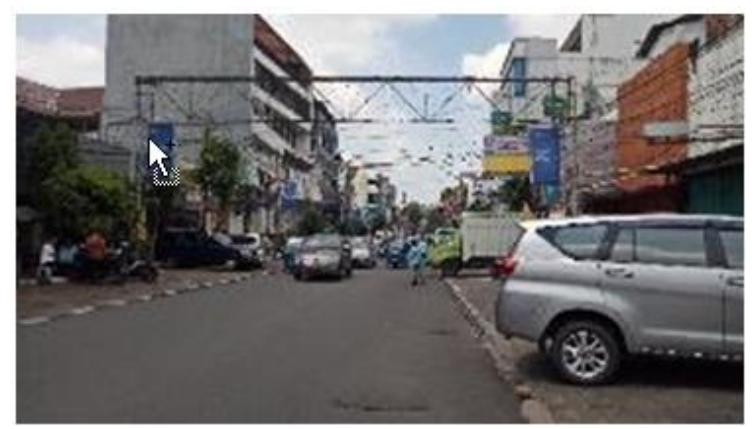

Gambar 5. Pertokoan dan Restoran-Restoran Sederhana

Sumber: Penulis, 2019

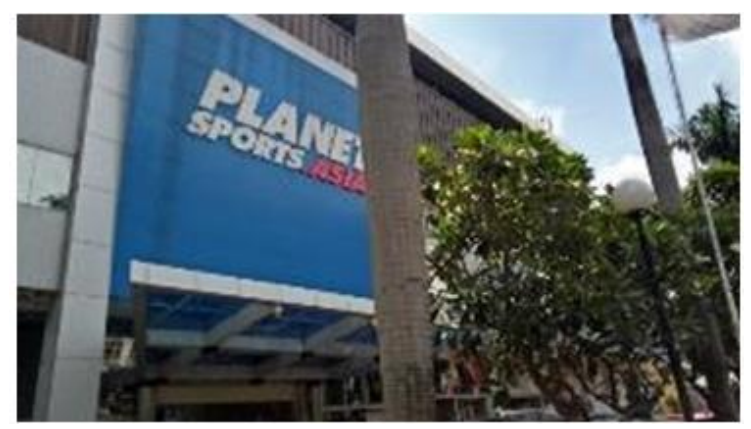

Gambar 7. Sport Retail Sarina

Sumber: Penulis, 2019

Dari hasil survei di atas, fungsi-fungsi di ingkungan sekitar cukup mendukung program reakreasi (Olahraga) dan memiliki sarana sebagai pendukung reakreasi.

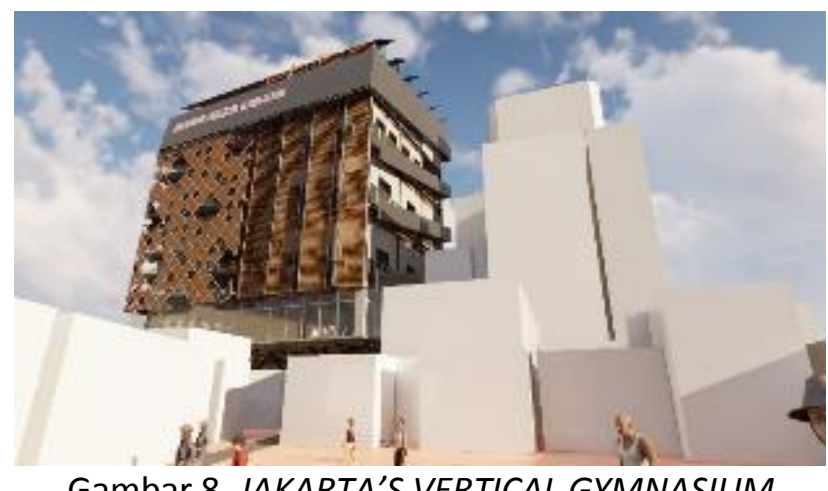

Gambar 8. JAKARTA'S VERTICAL GYMNASIUM

Sumber: Penulis, 2019

Dalam pengolahan bangunan olahraga pertimbangan volume dari ruang olahraga dan sarana pendukung olahraga, dengan adanya perencanaan penumpukan lapangan olaharaga membuat kebutuhan akan sirkulasi vertikal untuk keterjangkauannya khusunya untuk kaum disabilitas. 


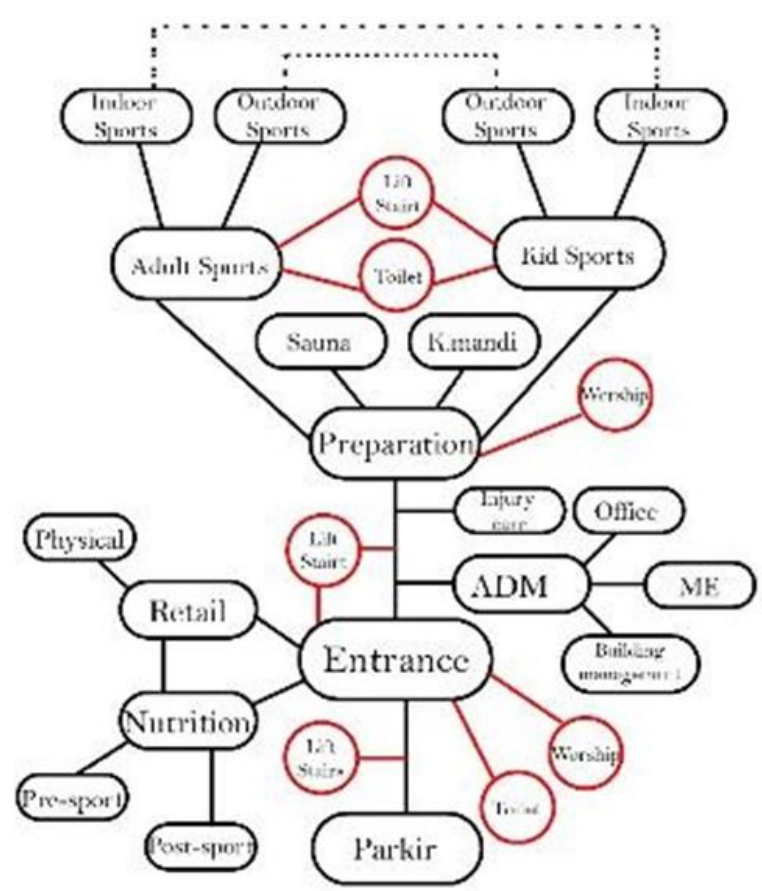

Gambar 9. Program ruang "Vertical Gymnasium"

Sumber: Penulis, 2019

Sedangkan untuk dapat meningkatkan kenyamanan penggunna, sarana olahraga yang tersusun meniggi membuat tantangan desain untuk menrencanakan bagaimana cahaya matahari tidak membuat padangna terhalangi dan kecepatan angin yang akan masuk ke area lapangam, perencanaan reflector cahaya untuk penerangan tidak langsung dan mencegaah silau di lapangan olahraga. Perencanaan sarana rekreasi perlu di pertimbangkan setiap pengguna agar dapat kesempatan dan kemudahan yang sama untuk menggunakan sarana olaraga yang ada.

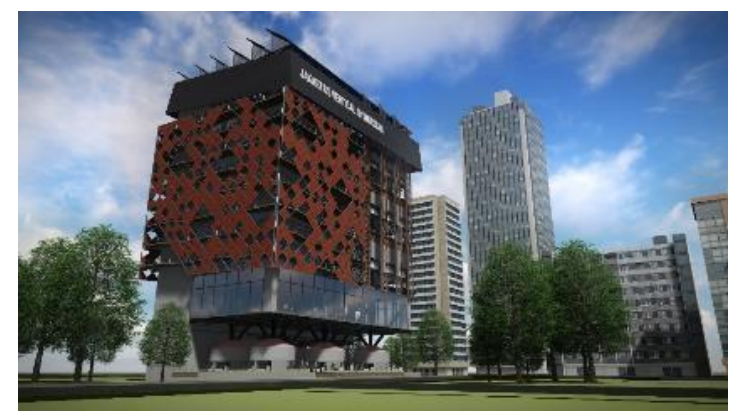

Gambar 10. JAKARTA'S VERTICAL GYMNASIUM Sumber: Penulis, 2019

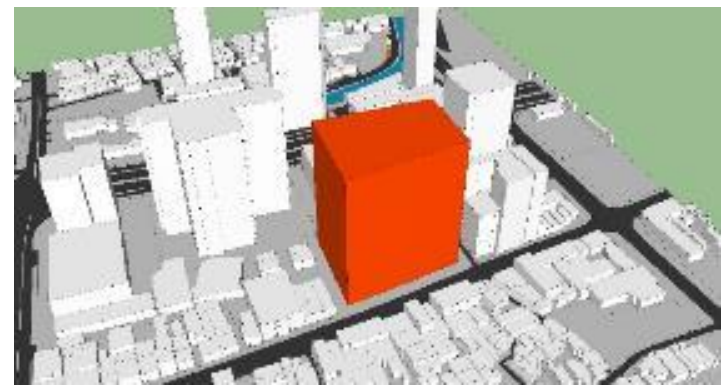

Gambar 11. Design Scheme1

Sumber: Penulis, 2019 
Blok massa dengan peraturan zonasi harus dimaksimalka untuk menyediakan sebanyakbanyaknya sarana olahrag aguna memamfaatkan setiap niali ekonomis dari tanah.

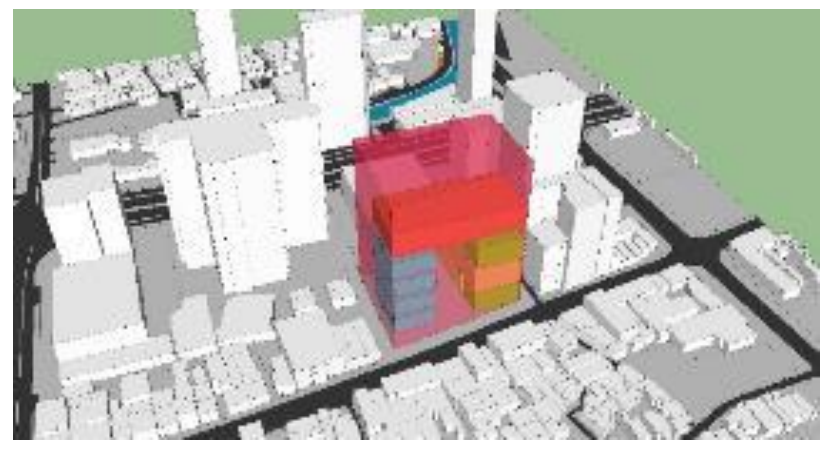

Gambar 12. Design Scheme2

Sumber: Penulis, 2019

Dengan menyusun lapangan olahraga terpilih dengan parameter umur untuk mengelompokkan setiap pengguna saran ini dari muda hingga dewasa.

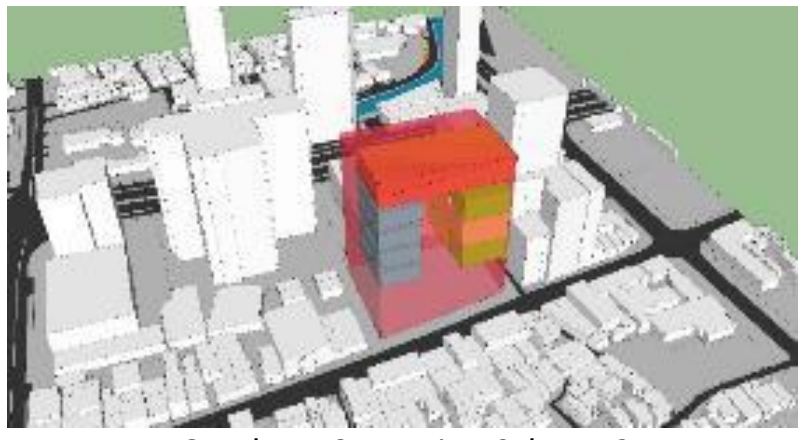

Gambar 13. Design Scheme3

Sumber: Penulis, 2019

Untuk tetap menyatukan lingkungan, fungsi pada abgian bawah untuk menjawab kebutuhan lingkungna untuk area untuk pedagang kaki lima.

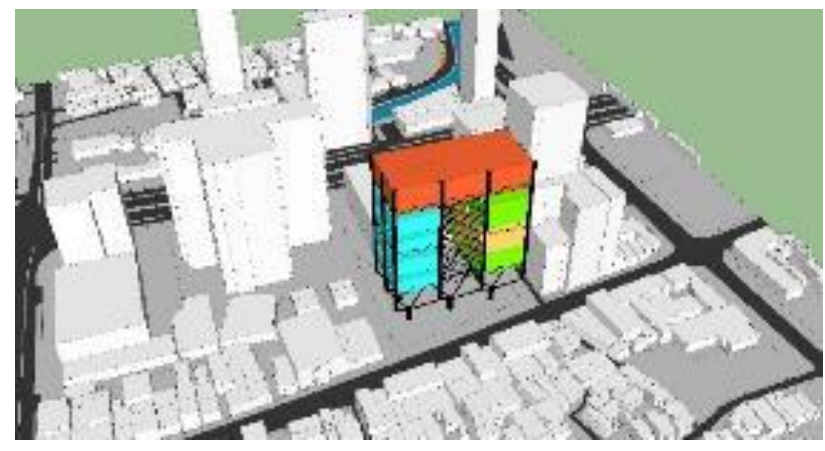

Gambar 14. Design Scheme4

Sumber: Penulis, 2019

Perencanaan struktur untuk memkasimalkan kedua program (rekreasi dan perdagangan) agar mendapat fleksibilitas masing-masing fungsi. 


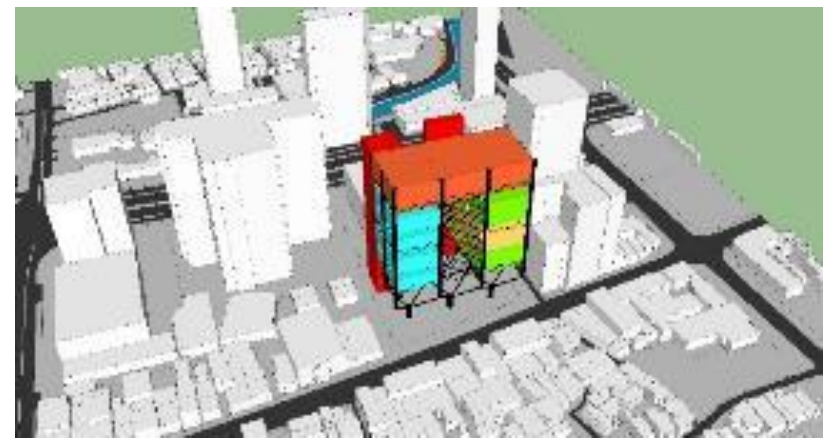

Gambar 15. Design Scheme5

Sumber: Penulis, 2019

Penambahan funsgsi pendukung untuk menjawab kebutuhan bangunan tinggi dari keselamatan keamanan dan trnasportasi vertikal.

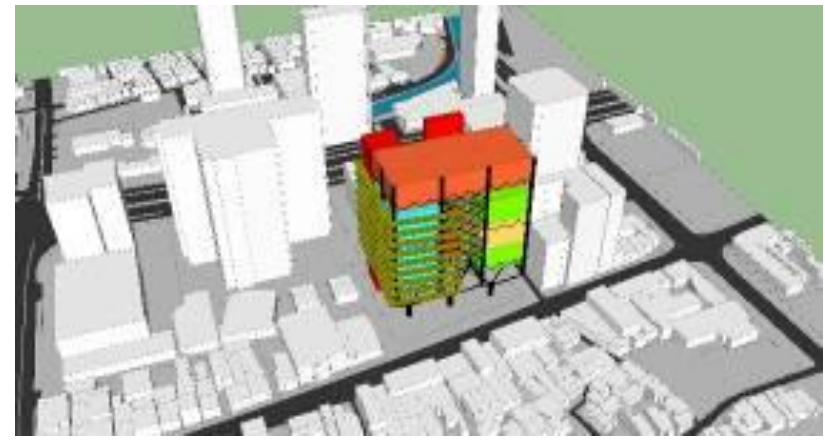

Gambar 16. Design Scheme6

Sumber: Penulis, 2019

Penyediaan ramp untuk membuat penggunan lebih bergerak dan sebagai fungsi ramp disabilitas.

\section{KESIMPULAN DAN SARAN}

Dengan terbentuknya Vertical Gymnasium di jakarta ini dapat mememenuhi kebutuhan rekreasi di tengha kota yang padat dati aktivitas perkantoran serta pmemerintahan, serta terciptanya komunitas baru untuk saling berinterksi dan berkolaborasi satu sama lain, diharapkan perkembangan reaksreasi di tengha kota ini akan semakin berkembang untuk teteap bisa mengimbangin kebutuhan rekreasi di tengah kota yang semakin padat.

\section{REFERENSI}

Kasali, R. (2012). Disruption. Jakarta. Hal.56 (15,02/2019 13:15)

Lee, C. \& Jacoby, S. (2011). Typological Urbanism and The Idea of the City. London: Wiley.

Jurnal Steel Construction "Today \& Tomorrow" tahun 2016

Jurnal Department of Sport and Recreation "Sports Dimensions Guide for Playing Areas" tahun 2016

https://www.cermati.com/artikel/generasi-millennial-wajib-olahraga-ini-alasannya

$(14,02 / 2019$ 22:15)

https://health.detik.com/berita-detikhealth/d-3719674/milenial-lebih-senang-olahraga-daripada-

politik-ini-pesan-dokter (14,02/2019 23:00)

https://www.csis.or.id (15,02/2019 01:15)

https://lifestyle.bisnis.com/read/20151113/220/491709/hasil-survei-kesadaran-hidup-sehat-

masyarakat-meningkat $(15,02 / 2019$ 12:01)

https://www.simplypsychology.org/maslow.html (15,02/2019 13:15)

https://sustainabledevelopment.un.org/sdgs (15,02/2019 15:36)

https://tipsmotivasi.com/2012/03/11/olahraga-meningkatkan-produktivitas-karyawan/ 
$(15,02 / 2019$ 17:23)

https://lifestyle.kompas.com/read/2018/01/13/083000920/kepribadian-ternyata-menentukanjenis-olahraga $(15,02 / 2019$ 18:37)

https://sejarahlengkap.com/olahraga/sejarah-olahraga-di-indonesia (15, 02/2019 22:00) https://guesfirmansyah.wordpress.com/sejarah-dan-perkembangan-olahraga-di-indonesia/ $(15,02 / 2019$ 22:00)

http://www.ikerenki.com/2013/12/pengertian-arti-makna-definisi-olahraga-menurut-ahlipakar.html (15, 02/2019 22:00)

https://tipsmotivasi.com/2012/03/11/olahraga-meningkatkan-produktivitas-karyawan/ $(16,02 / 201902: 04)$ 
